\title{
AN EPIDEMIOLOGICAL STUDY OF PULMONARY HYPERTENSION BY ECHOCARDIOGRAPHY IN TERTIARY CARE INSTITUTE, TAMILNADU, SOUTH INDIA
}

\author{
Alagarsamy Srinivasan ${ }^{1}$, Perumal Jaisankar ${ }^{2}$ \\ ${ }_{1}^{1}$ Senior Assistant Professor, Department of Cardiology, Thanjavur Medical College, Thanjavur, Tamilnadu, India. \\ ${ }^{2}$ Associate Professor, Department of Cardiology, Chengalpattu Government Medical College, Chengalpattu, Tamilnadu, India.
}

\begin{abstract}
BACKGROUND
Pulmonary hypertension is a severe progressive disease ultimately leading to right heart failure and death. There is paucity of data regarding pulmonary hypertension from the developing countries including India.

This retrospective descriptive study was carried out at a tertiary care institute with an objective of establishing the epidemiological data of pulmonary hypertension by Echocardiography.
\end{abstract}

ABSTRACT

\section{MATERIALS AND METHODS}

All patients who were referred for first time echo between January 2016 and December 2016 were included and analysed in this study. Echocardiogram was performed by consultant cardiologist using Philips HDIIXE and Aloka SSD-4000 machine following ASE guidelines. Pulmonary artery systolic was derived from right ventricular systolic pressure gradient from tricuspid regurgitation jet velocity by modified Bernoulli equation.

\section{RESULTS}

In our study, out of 17,625 cases, 281 (1.59\%) patients were diagnosed as pulmonary hypertension with slight preponderance to Female 145 (451.9\%) when compared to Male 125 (43.4\%). The commonest aetiology was Rheumatic Heart Diseases (37.7\%) followed by Coronary Artery Diseases (36.2\%) and COPD (11\%). Idiopathic pulmonary hypertension is seen in 5.3\% of patients. The mean age group in our study was 35 to 45 years.

\section{CONCLUSION}

Pulmonary hypertension is gaining renewed interest in recent times due to its devastating nature and availability of newer effective pulmonary vasodilator drugs. In this study, the commonest aetiology of pulmonary hypertension is treatable rheumatic heart disease and coronary artery disease. So, treatment of pulmonary hypertension with newer drugs and management of aetiological diseases like Rheumatic Heart Disease and Coronary Artery Disease will improve the survival of patients with pulmonary hypertension.

\section{KEY WORDS}

Pulmonary Hypertension, Rheumatic Heart Disease, Tricuspid Regurgitation, COPD.

HOW TO CITE THIS ARTICLE: Srinivasan A, Jaisankar P. An epidemiological study of pulmonary hypertension by echocardiography in tertiary care institute, Tamilnadu, South India. J. Evolution Med. Dent. Sci. 2018;7(36):3950-3953, DOI: $10.14260 /$ jemds $/ 2018 / 883$

\section{BACKGROUND}

Pulmonary Hypertension (PHT) is a debilitating disorder. Its severity is progressively increasing in nature. It shortens the lifespan of affected patients by right heart failure.(1) There is less data available regarding epidemiology of pulmonary hypertension and its multitude of aetiology in India.(2) Pulmonary hypertension burden in India is directly proportional to the prevalence of risk factor for development of pulmonary hypertension namely rheumatic heart disease, coronary artery disease, chronic obstructive pulmonary disease and untreated congenital heart disease.

The prevalence of risk factor for pulmonary hypertension in India is obtained from various community level studies in the first decade of $21^{\text {st }}$ century including 1.5 - 2 per 1000 for

'Financial or Other Competing Interest': None.

Submission 13-08-2018, Peer Review 25-08-2018,

Acceptance 27-08-2018, Published 03-09-2018.

Corresponding Author:

Dr. Perumal Jaisankar,

Associate Professor, Department of Cardiology,

Door No. F-16, Royal Denizen Apartment,

Pattabiraman Street, Thennur, Trichy-620017, Tamilnadu, India.

E-mail: jaicardio@gmail.com

DOI: $10.14260 /$ jemds $/ 2018 / 883$
RHD,(3) 4.2/ 1000 CHD,(4) 4.5 - 10.5 for ischaemic Heart disease.(5) There is changing trend in prevalence of Rheumatic Heart Disease and Ischaemic Heart Disease.(3) Prevalence of Rheumatic Heart Disease is declining in contrast to Ischaemic Heart Disease, which is on the raise.(6,7,8) The burden of pulmonary hypertension is likely to be different in India in contrast to the western world, where Idiopathic Pulmonary hypertension and pulmonary hypertension related to left heart disease, particularly coronary artery disease predominate. The predominant aetiology of Pulmonary hypertension in developing world like India is Rheumatic Heart Disease, COPD and Untreated CHD rather than primary Pulmonary hypertension and PHT related to left heart disease.(9)

Worldwide, pulmonary hypertension has received a great increase in awareness at the beginning of $21^{\text {st }}$ century. WHO developed new classification for Pulmonary hypertension in 2008.(10) There is renewed interest in the treatment of PHT because of effective pulmonary vasodilators like Sildenafil, tadalafil, Bosentan and Ambrisentan which are available worldwide. Overtime, the cost of these drugs have also fallen making it more affordable to majority of the patients in developing country like India. 
The right heart catheterisation is the method of choice for the diagnosis of Pulmonary hypertension.(11) But it is unsuitable for all studies, because of its invasive nature. In clinical practice screening and monitoring of pulmonary hypertension progression are done by Transthoracic Doppler echocardiography, because of its non-invasive nature. Some studies showed low sensitivity and specificity for diagnosis of Pulmonary hypertension by Transthoracic Doppler echocardiography. Meta-analysis showed that Transthoracic Doppler echocardiography have good sensitivity (83\%) and reasonable specificity of $72 \% .(12,13)$ Echocardiography registries in the developed world showed that Echocardiography was found to be useful and accurate in assessing Pulmonary Arterial Hypertension. $(14,15)$

\section{MATERIALS AND METHODS}

This was a retrospective descriptive study conducted in patients diagnosed as having pulmonary hypertension based on Echocardiographic evaluation during the period from January 2016 to December 2016. This study was done at Thanjavur Medical College and Hospital, which is a tertiary care centre with 1176 beds catering to the need of 69,000 patients per year. The data collected include age, sex, clinical diagnosis and findings on Transthoracic Echocardiography.

Echocardiography was performed using Philips HDIIXE and Aloka SSD-4000 ultrasound system by consultant cardiologists in accordance with American College of Cardiology/ American Society of Echocardiography guidelines.

\section{Definition and Classification of Pulmonary Hypertension}

Pulmonary Hypertension is defined as documented elevated RVSP $>35 \mathrm{mmHg}$ on transthoracic echocardiography Doppler study in the absence of pulmonary stenosis and acute right heart failure. Doppler Echo estimates the Pulmonary Artery Systolic Pressure (PASP) by measuring the maximum velocity of TR (Tricuspid Regurgitation). The Transtricuspid pressure gradient will be calculated using the modified Bernoulli equation $\left(4 \mathrm{~V}^{2}\right) .{ }^{(16)}$ The tricuspid regurgitation gradient was added to the Right Atrial Pressure (RAP) to derive Pulmonary Artery Systolic Pressure (PASP) using the formula $\left(\mathrm{PASP}=4 \mathrm{~V}^{2}+\mathrm{RAP}\right)$. In the absence of pulmonary outflow obstruction, PASP equates to RVSP. The respiratory variation of size of inferior vena cava in M-mode was used to estimated RAP.(17)

In our study different echocardiographic windows like parasternal RV inflow, parasternal short axis and apical four chamber window were used to determine the highest velocity of Tricuspid regurgitation, which reflect RVSP/ PASP.(18) Pulmonary hypertension was defined as mild if RVSP was 36$50 \mathrm{mmHg}$, moderate if RVSP was 51-60 $\mathrm{mmHg}$ and severe if RVSP was $>60$ mmHg.(19)

The updated classification system for Pulmonary Hypertension (Dana Point 2008) was applied to describe the different aetiologies of Pulmonary Hypertension. In this WHO - Dana point classification, PHT was classified into 5 groups based on the aetiology-

$\begin{array}{lll}\text { Group I } & - & \text { Idiopathic. } \\ \text { Group II } & - & \text { Left heart disease. } \\ \text { Group III } & - & \text { Chronic lung disease. } \\ \text { Group IV } & - & \text { Chronic thromboembolism. } \\ \text { Group V } & - & \text { Multifactorial. }\end{array}$

In a developing country like India, still RHD is the predominant disease which affect valves on left side of the heart. Hence, Group II is further divided into Rheumatic heart disease as one subgroup and Coronary artery disease and Cardiomyopathies as another subgroup in our study.

\section{RESULTS}

Out of 17,625 consecutive patients who underwent echocardiography in our study period, 281 (1.59\%) patients were diagnosed as pulmonary hypertension. Out of 281 patients 125 (43.4\%) were male, 145 (51.6\%) were female and $11(4.9 \%)$ were in paediatric age group.

Out of the 281 patients with pulmonary hypertension, 208 (74\%) patients had left heart disease as the aetiology of pulmonary hypertension. RHD 106 (37.7\%) was the leading aetiology of left heart disease, which leads Pulmonary Hypertension followed by coronary artery disease 102 (36.2\%) (Table I).

$30(11 \%)$ patients were associated with Chronic Respiratory diseases. 15 (5.3\%) and 8 (2.2\%) cases were due to Idiopathic pulmonary hypertension and chronic thromboembolism respectively. Even though females were more commonly affected by pulmonary hypertension, but pulmonary hypertension due to coronary artery disease $(65 \%)$ and chronic respiratory disease $(60 \%)$ predominantly affected male gender. RHD (71.6\%), Idiopathic PHT (86.6\%) and chronic thromboembolism (75\%) were common in females.

196 (69.6\%) of patients with PHT belonged to the productive age group of 20 - 60 years. $44.4 \%$ (125) patients were in 40 - 60 years and $25.2 \%$ (71) were in 20 - 40 years of age group. RHD (41\%) and Idiopathic PHT (74\%) were predominantly seen in younger age group of 20 - 40 years. Coronary Artery disease (47\%) and Chronic Respiratory disease $(34 \%)$ were commonly seen in $40-60$ age group. (Table II, Fig. 2).

194 (69\%) patients were diagnosed as mild PHT, where $68(24.1 \%)$ and $19(6.1 \%)$ were suffering from moderate and severe pulmonary hypertension respectively (Fig. I). Commonest cause of severe pulmonary hypertension in our study was RHD (7 cases) whereas coronary artery disease was the commonest cause of mild pulmonary hypertension (79 cases).

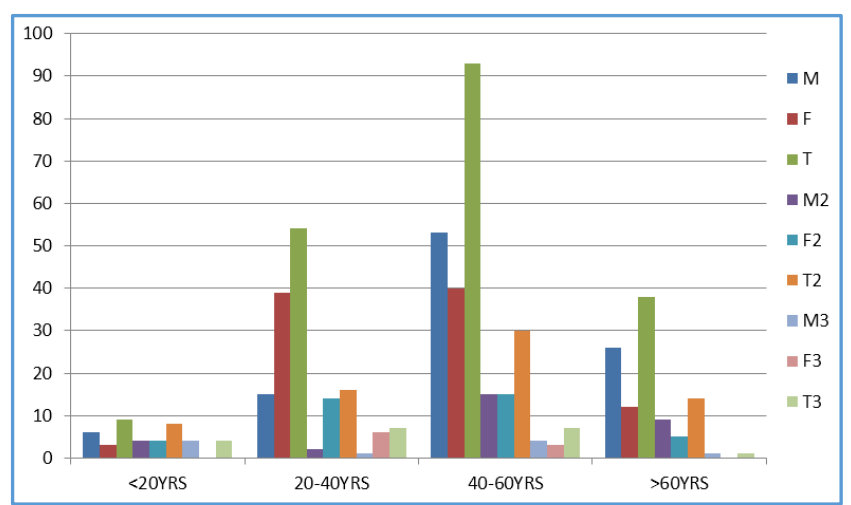

Figure 1. Distribution of Age, Sex and Severity of PHT. (M-Male, mild PHT; M2-Male, Moderate PHT; M3-Male, severe PHT) (F-Female, mild PHT; F2-Female, Moderate PHT; F3-Female, severe PHT) (T-Total, mild PHT; T2- Total, Moderate PHT; T3-Total, severe PHT) 


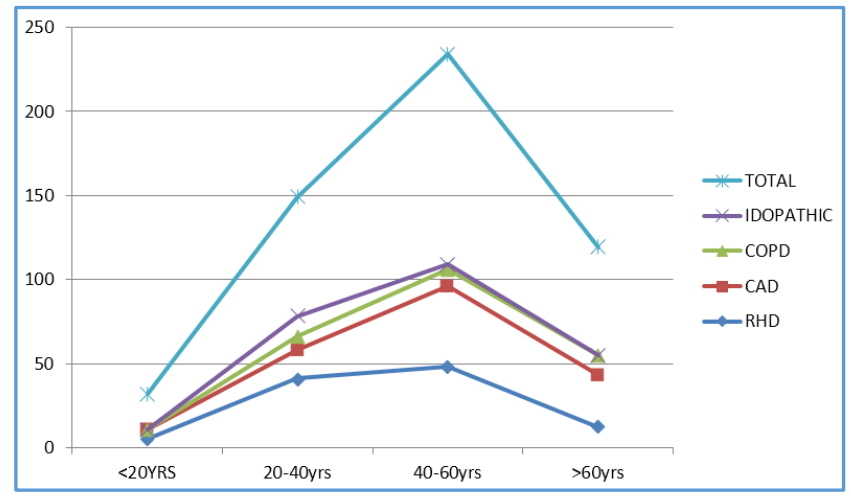

Figure 2. Age Wise distribution of various Aetiologies of PHT

\begin{tabular}{|c|c|c|c|c|}
\hline Aetiology & Male & Female & Paediatric & Total \\
\hline RHD & $28(26.4)$ & $76(71.6)$ & $2(1.8)$ & $106(37.7)$ \\
\hline CAD and DCMP & $67(65.6)$ & $32(31.3)$ & $3(0.95)$ & $102(36.26)$ \\
\hline Congenital HD & $4(33.3)$ & $2(16.6)$ & $6(50.5)$ & $12(4.25)$ \\
\hline COPD & $18(6.0)$ & $12(40 \%)$ & - & $30(11 \%)$ \\
\hline Idiopathic & $2(13.3)$ & $13(86.6)$ & - & $15(5.3 \%)$ \\
\hline Thromboembolism & $2(25 \%)$ & $6(7.5)$ & - & $8(2.8 \%)$ \\
\hline Others & 1 & 7 & - & 8 \\
\hline Total & $\begin{array}{c}\mathbf{1 2 2} \\
(\mathbf{4 3 . 4 \% )})\end{array}$ & $\begin{array}{c}\mathbf{1 4 8} \\
\mathbf{( 5 1 . 6 \% )}\end{array}$ & $\mathbf{1 1} \mathbf{( 4 . 9 \% )}$ & $\mathbf{2 8 1}$ \\
\hline \multicolumn{5}{|l}{ Table I. Aetiology and Sex Distribution of PHT } \\
\hline
\end{tabular}

\begin{tabular}{|c|c|c|c|c|c|}
\hline Age & RHD & CAD & COPD & Idiopathic & Total \\
\hline$<20$ years & $5(4.7)$ & $6(5.8)$ & - & - & $21(7.4)$ \\
\hline $\begin{array}{c}20-40 \\
\text { yrs. }\end{array}$ & $41(38.6)$ & $17(16.6)$ & $8(26 \%)$ & $12(74 \%)$ & $71(25.2)$ \\
\hline $\begin{array}{c}40-60 \\
\text { yrs. }\end{array}$ & $48(45.2)$ & $48(47.0)$ & $10(34 \%)$ & $3(25 \%)$ & $125(44.4)$ \\
\hline$>60$ yrs. & $12(11.3)$ & $31(30.3)$ & $12(42 \%)$ & - & $64(22.7)$ \\
\hline \multicolumn{6}{|c|}{ Table II. Age Wise distribution of PHT } \\
\hline
\end{tabular}

\section{DISCUSSION}

Worldwide, Pulmonary hypertension has received a great increase in awareness at the beginning of $21^{\text {st }}$ century. The prevalence of Pulmonary hypertension in India varies geographically according to the risk factor and diseases which predispose to PHT. There is change in the prevalence of risk factors for Pulmonary hypertension in developing countries like India. $(3,4,5)$ There is a decline in infective aetiology such as RHD and pulmonary tuberculosis, whereas non-communicable disease such as coronary artery disease are increasing in its prevalence. Obviously, there will be similar change in aetiology of Pulmonary Hypertension also. Diagnosis of pulmonary hypertension is challenging in early stages due to the subtle clinical features and in more advanced stage of disease due to lack of awareness and low index of suspicion by primary physicians. All suspected patients could not access and afford vital echo and tertiary care services.

The prevalence of pulmonary hypertension in our study is $1.59 \%$, which is slightly lower than the study by Eduardo et al.(20) Our study population comprises in patients, which is different from general population study. Geoff Strange et al(21) reported 9.1\% pulmonary hypertension and 6.6 were reported in INCIPIT Study.(22)

The commonest aetiology of Pulmonary hypertension in our study is left heart disease $74 \%$, which is slightly higher than 59\% reported in PROKERALA registry(15) and similar to 69\% in PAPUCO study in Africa by Friedrich Thieneman et al(14) and $68 \%$ reported by Geoff Strange et al.(22) But the commonest aetiology in western and developed countries is idiopathic pulmonary hypertension.(23) $64 \%$ of patients with Pulmonary hypertension were diagnosed as Idiopathic Pulmonary hypertension by Pavel Jansa et al.(23) But only $5.3 \%$ cases were due to Idiopathic Pulmonary hypertension in our study. PROKERALA registry reported $21.2 \%$ cases and PAPUCO study reported $2 \%$ cases as Idiopathic Pulmonary Hypertension.

$11 \%$ cases of Pulmonary Hypertension in our study were caused by chronic respiratory disease, which is similar to $11 \%, 13.3 \%$ reported by Friedrich et al(14) and Sri Hariharan et al.(15) Eduardo et al reports lower incidence of 5.9\% cases due to chronic respiratory disease, $(20)$ similar to $9 \%$ by Geoff Strange et al.(21)

In our study chronic thromboembolism contribute $2.8 \%$ cases of Pulmonary hypertension, which is similar to African PAPUCO study $2 \%$ and $2.7 \%$ in Australian study by Geoff Strange et al.(21) Even though there is decline in the incidence of RHD in India,(24) the commonest case of left heart disease which predispose to PHT is RHD (27\%) when compared to coronary artery disease (23\%).

More than fifty percent $(51.6 \%)$ of patients with pulmonary hypertension were females in our study, whereas $43.4 \%$ of patients were males. Female preponderance was reported in most of the studies Wook-Jin Ching et al.(15,26,27) Left heart disease and COPD were predominantly seen in males, whereas idiopathic PHT, thromboembolism and connective tissue disorders were commonly seen in females. Similar distribution is seen in PROKERALA study.(15) Pulmonary hypertension is not only a devastating disease, but also affects young and middle aged population in 20 - 50 years' age group. In our study, mean age group is $35-45$ years, which is the productive period of human life.

\section{Limitations}

This is an analytical study that reflects a single tertiary care institute retrospective observation. It is not a populationbased study. This may result in several bias. Moreover, symptomatic status, clinical details, clinical outcome/ followup information were not available. Even though, Echo remains the important diagnostic tool in the diagnosis of Pulmonary hypertension, Gold standard method for diagnosis is right heart catheterisation which was not used in our study.

\section{CONCLUSION}

Pulmonary hypertension is gaining renewed interest in recent times due to its devastating nature, affecting middle age productive population and availability of effective newer drugs. Rheumatic Heart Disease and Coronary Artery Disease are the most common aetiology of pulmonary hypertension in India rather than Idiopathic Pulmonary hypertension. Treatment of Pulmonary Hypertension with newer drugs and management of risk factors like Rheumatic Heart Disease, Coronary Artery Disease and COPD will improve the survival of the patients with pulmonary hypertension. 


\section{REFERENCES}

[1] Simonneau G, Gatzoulis MA, Adatia I, et al. Updated clinical classification of pulmonary hypertension. J Am Coll Cardiol 2013;62(Suppl 25):D34-41.

[2] Sliwa K, Carrington MJ, Becker A, et al. Contribution of the human immunodeficiency virus/acquired immunodeficiency syndrome epidemic to de novo presentations of heart disease in the Heart of Soweto Study cohort. Eur Heart J 2012;33(7):866-74.

[3] Sliwa K, Wilkinson D, Hansen C, et al. Spectrum of heart disease and risk factors in a black urban population in South Africa (the Heart of Soweto Study): a cohort study. Lancet 2008;371(9616):91522.

[4] Stewart S, Mocumbi AO, Carrington MJ, et al. A not-sorare form of heart failure in urban black Africans: pathways to right heart failure in the Heart of Soweto Study cohort. Eur J Heart Fail 2011;13(10):1070-7.

[5] Mocumbi AO, Lameira E, Yaksh A, et al. Challenges on the management of congenital heart disease in developing countries. Int J Cardiol 2011;148(3):285-8.

[6] Patel DC, Patel NI, Patel JD, et al. Rheumatic fever and rheumatic heart disease in school children of Anand. J Assoc Physicians India 1986;34(12):837-9.

[7] Thakur JS, Negi PC, Ahluwalia SK, et al. Epidemiological survey of rheumatic heart diseases among school children in the Shimla Hills of northern India: prevalence and risk factors. J Epidemiol Community Health 1996;50(1):62-7.

[8] Lalchandani A, Kumar HR, Alam SM, et al. Prevalence of rheumatic fever and rheumatic heart disease in rural and urban school children of district Kanpur (UP). Indian Heart J 2000;52:672.

[9] Karaye KM, Saidu H, Bala MS, et al. Prevalence, clinical characteristics and outcome of pulmonary hypertension among admitted heart failure patients. Ann Afr Med 2013;12(4):197-204.

[10] Simonneau G, Robbins IM, Beghetti M, et al. Updated clinical classification of pulmonary hypertension. J Am Coll Cardiol 2009;54(Suppl 1):S43-S54.

[11] Galie N, Hoeper MM, Humbert M, et al. Guidelines for the diagnosis and treatment of pulmonary hypertension: the Task Force for the Diagnosis and Treatment of Pulmonary Hypertension of the European Society of Cardiology (ESC) and the European Respiratory Society (ERS), endorsed by the International Society of Heart and Lung Transplantation (ISHLT). Eur Heart J 2009;30(20):2493-537.

[12] D'Alto M, Romeo E, Argiento P, et al. Accuracy and precision of echocardiography versus right heart catheterization for the assessment of pulmonary hypertension. Int J Cardiol 2013;168(4):4058-62.

[13] Janda S, Shahidi N, Gin K, et al. Diagnostic accuracy of echocardiography for pulmonary hypertension: a systematic review and meta-analysis. Heart 2011;97(8):612-22.

[14] Thienemann F, Dzudie A, Mocumbi AO, et al. Rationale and design of the Pan African Pulmonary hypertension Cohort (PAPUCO) study: implementing a contemporary registry on pulmonary hypertension in Africa. BMJ 2014;4: e005950.
[15] Harikrishnan S, Sanjay B, Ashishkumar M, et al. Pulmonary Hypertension Registry of Kerala (PROKERALA) - Rationale, design and methods. Indian Heart J 2016;68(5):709-15.

[16] Sciomer S, Magrì D, Badagliacca R. Non-invasive assessment of pulmonary hypertension: Dopplerechocardiography. Pulm Pharmacol Ther 2007;20(2):135-40.

[17] Beigel R, Cercek B, Luo H, et al. Noninvasive evaluation of right atrial pressure. J Am Soc Echocardiogr 2013;26(9):1033-42.

[18] Quiñones MA, Otto CM, Stoddard $M$, et al. Recommendations for quantification of Doppler echocardiography: a report from the Doppler Quantification Task Force of the Nomenclature and Standards Committee of the American Society of Echocardiography. J Am Soc Echocardiogr 2002;15(2):167-84.

[19] Schachna L, Wigley FM, Chang B, et al. Age and risk of pulmonary arterial hypertension in scleroderma. Chest 2003;124(6):2098-104.

[20] Moreira EM, Gall H, Leening MJ, et al. Prevalence of pulmonary hypertension in the general population: the Rotterdam study. PLoS One 2015;10(6): e0130072.

[21] Strange G, Playford D, Stewart S, et al. Pulmonary hypertension: prevalence and mortality in the Armadale echocardiography cohort. Heart 2012;98(24):1805-11.

[22] Enea I, Ghio S, Bongarzoni A, et al. Echocardiographic alterations suggestive of pulmonary hypertension in the Italian ultrasonography laboratories. Epidemiological data from the INCIPIT study (INCidence of Pulmonary Hypertension in Italian ultrasonography laboratories). G Ital Cardiol (Rome) 2010;11(5):402-7. (Article in Italian).

[23] Jansa P, Jarkovsky J, Al-Hiti H, et al. Epidemiology and long-term survival of pulmonary arterial hypertension in the Czech Republic: a retrospective analysis of a nationwide registry. BMC Pulm Med 2014;14:45.

[24] Abrar A, Khan S, Ur Rehman M, et al. Frequancy of Rheumatic heart diseases in patients undergoing Echocardiography in District Dera Ismail Khan. Gomal J Med Sci 2014;12(3):147-50.

[25] Wook-Jin C, Park, Jeon CH, et al. Baseline characteristics of the Korean registry of pulmonary arterial hypertension. J Korean Med Sci 2015;30(10):1429-38.

[26] Fayngersh V, Drakopanagiotakis F, McCool F, et al. Pulmonary hypertension in a stable community-based COPD population. Lung 2011;189(5):377-82.

[27] Andersen KH, Iversen $M$, Kjaergaard J, et al. Prevalence, predictors and survival in pulmonary hypertension related to end-stage chronic obstructive pulmonary disease. J Heart Lung Transplant 2012;31(4):373-80. 